\title{
QUAIS SÃO AS NOSSAS DIFERENÇAS? REFLEXÕES SOBRE A CONVIVÊNCIA COM O DIVERSO EM ESCOLAS ITALIANAS
}

\author{
Maria Beatriz Rodrigues \\ Cooperativa Social Ce.Se.Co., Genova, Itália
}

RESUMO: O artigo considera a lei Basaglia, do fechamento dos manicômios, como um divisor de águas na sociedade italiana no tocante ao enfrentamento do tema diversidade. Examina, baseado em uma experiência de três anos em escolas italianas, a operacionalização de outra lei que segue os mesmos princípios e prevê a freqüência de todas as crianças, normo- e infra- dotadas, em escolas regulares e que aboliu as chamadas classes especiais. Problematiza o conceito atual de diversidade tendo em vista a crescente presença de um novo grupo de diversos nas escolas, os estrangeiros, e propõe, a partir da leitura de Foucault sobre o direito à saúde, uma linha móvel para o entendimento da diversidade.

PALAVRAS-CHAVE: diversidade; educação; interculturalidade.

\section{WHAT ARE OUR DIFFERENCES? REFLECTIONS ABOUT COHABITATION WITH DIVERSITY IN ITALIAN SCHOOLS}

ABSTRACT: The article considers the so called Basaglia's law that closed the asylums as a watershed in the Italian society. It regards the approach to the theme of diversity. Based on an experience of three years in the Italian schools the article examines the practice of another law that foresees the attendance by all children, normal or handicapped, in regular schools instead of special ones. It poses the problematic of the current concept of diversity and proposes from the reading of Foucault on the right to health, a mobile line for the understanding of diversity.

KEY WORDS: diversity; education; interculturality.

$\mathrm{O}$ artigo discute a diversidade em escolas italianas. Considera como background a lei Basaglia, de 1978, que abriu a sociedade italiana à convivência com o diverso, assim como uma lei posterior, $\mathrm{n}^{\circ} 104$ de 1992, que segue os mesmos princípios, e prevê a freqüência de todos os alunos, infra ou normo-dotados intelectualmente, na mesma classe. A lei Basaglia aboliu os manicômios, a lei $\mathrm{n}^{\circ} 104$, as classes especiais. São duas leis, produto de movimentos sociais, que buscam aceitar o diverso e conviver com as idiossincrasias próprias das diferenças.

Ilustramos essa realidade com uma experiência de três anos de trabalho em psicologia e educação no contexto sócio-educativo italiano, com o acompanhamento de crianças e adolescentes com déficits de aprendizagem. A partir dessa experiência constatamos que a diversidade, conceito dinâmico por excelência, hoje é representada na escola, não somente por crianças portadoras de deficiências, mas também pela presença significativa e crescente de estrangeiros em classe. Não generalizamos o estrangeiro, o doente mental e o portador de deficiência, mas consideramos os estrangeiros como um novo grupo em situação de diversidade e de desvantagem social.

Individuamos o contorno de uma nova fronteira da diversidade, ou seja, a presença do estrangeiro que no interior da escola não encontra plena integração. O direito à educação na Itália é garantido a todos, porém, o debate de como afrontar essa integração após um primeiro impacto emocional, encontra-se ainda em estado embrionário. Incluindo o tema imigração na discussão da escola, tocamos um ponto crucial de atualização do tema diversidade.

Consideramos a escola como ponto de partida, mas ampliamos a discussão em Psicologia Social e tratamos diversidade como algo dinâmico e essencialmente dependente de mudanças sociais, que pode iniciar com a experiência da criança na escola mas que estende-se para outras esferas da vida com o passar dos anos e a convivência com diversidades raciais, religiosas, culturais, sexuais. Assim sendo, enfatizamos a importância da educação para a aceitação do diverso e, ao mesmo tempo, contextualizamos essa problemática analisando os momentos históricos e sociais que levaram a aprovação da lei Basaglia nos anos 1970, e o momento atual com as dificuldades de integração dos alunos estrangeiros nas escolas italianas.

\section{Notas sobre o Sistema de Saúde Italiano dos anos 1970 aos dias atuais}

Para introduzir a questão do diverso na escola italiana, parece imprescindível o referimento a lei Basaglia ${ }^{1}$, conhecida como a lei do fechamento dos manicômios. $\mathrm{O}$ background econômico-social da Itália que a propiciou mereceria um percurso arqueológico mais profundo, mas por questões práticas de discussão devemos considerar que nossa história inicia com a lei Basaglia. Porém, a alusão à Itália do pós-guerra, com o estabelecimento do Welfare State, assim como a transformação da Itália camponesa em Itália industrial é imprescindível. O próprio Basaglia considerava esse momento de lutas operárias e consolidação de uma sociedade de classes sociais mais definidas como uma significativa mudança cultural e um dos pontos focais de seu projeto de Psiquiatria Democrática.

A lei Basaglia, em essência, impede o internamento compulsório de doentes mentais, ou seja, estabelece a

${ }^{1}$ Franco Basaglia (1924-1980) médico psiquiatra italiano que lutou pela desinstitucionalizaçao da doença mental e de seus depósitos, os manicômios, que como resultado de seu trabalho foram gradativamente fechados na Itália a partir da aprovação da lei de sua autoria, $\mathrm{n}^{\circ} 180$, em maio de 1978. 
voluntariedade do doente para o internamento. Prevê também a convivência do doente na sociedade, não mais confinado por longos períodos em hospitais psiquiátricos. Substituiu uma lei precedente, de 1904, que considerava legítimo o internamento mediante o reconhecimento médico da periculosidade de uma pessoa para si e para os outros. É uma lei que toca no poder da medicina e nos dogmas de cura, recolocando o doente em seu lugar de sujeito, não mais de paciente. $\mathrm{O}$ papel dos profissionais de saúde muda drasticamente, passando do exercício do poder baseado no saber, para o desafio de usar principalmente o saber na recuperação e potencialização dos sujeitos.

Partindo de um referencial claramente anti-psiquiátrico e entendendo a loucura como uma condição humana, exatamente como o é a razão, Basaglia coloca no centro da questão loucura/enlouquecimento o sujeito e a comunidade. "Curar é papel de todos", essa premissa exige uma grande transformação nos papéis institucionais e sociais. O sujeito doente pode e deve escolher quando ser contido, procurando ajuda voluntariamente quando pensa ser necessário; e a comunidade deve e pode acolher esses sujeitos em seu cotidiano, ajudando-os e aceitandoos com suas diferenças.

Basaglia contava um episódio de um taxista de Trieste, que ao aceitar em seu carro um passageiro que solicitava ser levado a Beirute, reconheceu neste "tipo estranho" um provável paciente do manicômio aberto. Girou pela cidade e depois o reconduziu ao hospital. Essa situação reflete a mudança de atitude das pessoas frente aos doentes, depois do trabalho de conscientização da luta antimanicomial. Em relativamente poucos anos o medo, a rejeição e outros sentimentos de intolerância cederam espaço à compreensão e aceitação. "Isso é curar, o taxista tomou conta de uma pessoa que queria ir a Beirute de táxi. Um outro teria escapado, ou teria chamado a policia, certamente piorando as coisas" (Basaglia, citado em Gianella, 1977, p.84).

Esse movimento corajoso foi finalmente colocado em prática nacionalmente em maio de 1978, através da lei 180, após 16 anos de intensas lutas da parte dos profissionais envolvidos $^{2}$. Os focos do movimento concentravam-se principalmente nos hospitais de Gorizia, Parma e Trieste e propunham a gradual transformação dessas estruturas em comunidades terapêuticas e/ou casas para ex-pacientes sem destinação. O Hospital Psiquiátrico San Giovanni³ em Trieste, foi o primeiro manicômio a ser fechado na Europa em conseqüência de uma luta anti-institucional (Giannella, 1977).

Os profissionais do movimento sofreram muitas retaliações a ponto de serem acusados de cumplicidade em atentados. O momento político nacional era muito conturbado pela ação de movimentos extremistas, tanto

\footnotetext{
${ }^{2} 27$ psiquiatras, 11 assistentes sociais, 3 sociólogos, um psicólogo, um psicopedagogo e 350 enfermeiros.

${ }^{3}$ Em 1971 quando Basaglia iniciou seu trabalho em Trieste, o Hospital San Giovanni contava com 1298 internos, sendo dois terços dos mesmos internados compulsoriamente. Seis anos depois, através de um trabalho contínuo de abertura do hospital e, finalmente, concretizando seu fechamento, existiam ainda 126 internos, mais da metade deles voluntários (Giannella, 1977).
}

de direita quanto de esquerda. Em um atentado à bomba próximo a Gorizia onde foram mortos três policiais, alguns jornais escreveram sobre a suposta participação de um membro do hospital de Basaglia (Ibid). Mesmo depois desses fatos, uma intensa campanha midiática que mostrava os horrores no interior dos manicômios, associada a muitos debates, restituiu ao país o clima favorável à aprovação da lei. Certamente muitos problemas ocorreram em sua operacionalização, muitos persistem até hoje, como a morosidade burocrática, inconstante vontade política, grandes diferenças regionais, que fazem com que continuem existindo alguns manicômios, principalmente no sul do país, que não conseguiram acompanhar o processo de desinstitucionalização.

Porém, é importante ressaltar a difusão dessa lei e sua persistência mesmo depois da morte de seu mentor ${ }^{4}$ e de muitas e constantes mudanças na política nacional. Basaglia era um profissional inovador, com forte influência política de esquerda, e que conseguiu ser apoiado em seu projeto por um governo muito divergente ideologicamente. O impacto e a consolidação da lei Basaglia na sociedade italiana é notável, a ponto de abrir portas para outras leis semelhantes. A exigência de uma atenção diferenciada ao doente mental, projetada e praticada pelo trabalho de Basaglia, estendeu-se nas últimas décadas a outros grupos sociais em dificuldade ou risco, como por exemplo crianças e adolescentes doentes, limitados, abusados, drogados.

Hoje na Itália é inconcebível que uma criança portadora de sofrimento psíquico ou limitada intelectualmente não freqüente a escola pública, como todas as outras crianças da sua idade ${ }^{5}$, assim como é inconcebível confinar um doente mental em um manicômio ou um tóxico-dependente em uma clinica que utiliza métodos violentos de contenção. Todas essas garantias sociais, certamente não se devem somente ao aspecto legal, mas sim a uma profunda mudança de concepção.

A lei da escola que terminou com as classes especiais, considera pessoa portadora de deficiência, aquela que apresenta alguma limitação física, psíquica ou sensorial, estável ou progressiva, que causa dificuldade de aprendizagem, de relacionamento ou de integração no trabalho, a ponto de determinar um processo de desvantagem social ou marginalização. A lei é finalizada a: garantir o pleno respeito à dignidade e aos direitos de liberdade e de autonomia das pessoas portadoras de deficiência e promover a plena integração na família, na escola, no trabalho e na sociedade; remover condições invalidantes que impedem o desenvolvimento, a autonomia, a participação da pessoa portadora de deficiência na coletividade e a realização de seus direitos civis, políticos e patrimoniais; assegurar a recuperação

\footnotetext{
${ }^{4}$ Franco Basaglia morreu aos 56 anos, em 1980, apenas dois anos após a aprovação da lei 180 .

${ }^{5} \mathrm{Na}$ Itália todas as crianças com seis anos devem ir a escola, é a chamada "scuola d'obbligo", ou seja, a escola é obrigatória à todos dos seis aos dezesseis anos. Uma nova diretriz do atual governo pretende ampliar esse limite até os 18 anos. O controle é feito pela prefeitura que mantém o cadastro de todos os cidadãos ou residentes. Se uma família não manda os filhos a escola está sujeita a controle e, em caso de resistência, pode responder
} 
funcional e social das pessoas portadoras de deficiências, através de serviços de prevenção, cura e reabilitação, além da tutela jurídica e econômica; garantir ações voltadas à superação da marginalização e da exclusão social ${ }^{6}$.

Para ter direito aos programas públicos de assistência, o sujeito portador de deficiência passa por uma avaliação multidisciplinar, realizada por profissionais da rede pública de saúde, chamada "perfil dinâmico-funcional". Após a confirmação de diagnóstico e prognóstico, é elaborado um programa personalizado envolvendo a escola, outros profissionais e instituições qualificadas para o trabalho com o sujeito. São previstas três atualizações formais desta avaliação: aos 10, aos 14 e aos 18 anos.

Em termos práticos, a lei prevê auxílios ao desenvolvimento pessoal e social desses sujeitos, podendo ser de tipo sócio-psico-pedagógico, doméstico, e/ou econômico. O auxilio sócio-psico-pedagógico envolve a estimulação para o desenvolvimento integral do sujeito através de ações terapêuticas e socializadoras, apoio ao cumprimento de exigências escolares, estímulo ao exercício físico, entre outras modalidades possíveis de intervenção. $\mathrm{O}$ apoio doméstico, concedido a famílias com poucos recursos econômicos ou pessoas solitárias e dependentes, pode ser do tipo assistencial e/ou ligado às tarefas domésticas e operacionais. O auxílio econômico pode ser através de bolsas de estudo, bônus para compra de livros, alojamentos em casas subsidiadas pelo estado, pensões de invalidade, entre outras.

A lei da escola gerou a necessidade de uma estrutura para atendimento dessa nova demanda. Criaram-se as cooperativas sociais, ou seja, grupos de profissionais em educação, psicologia, psicomotricidade, entre outros, reunidos para atender escolas ou famílias necessitadas. Esses profissionais são conhecidos genericamente como educadores e desenvolvem o trabalho de integração e educação dessas crianças e adolescentes em classe, conjuntamente com professores. Estabeleceu-se uma sinergia entre público e privado, e uma descentralização do sistema sócio-educativo, sendo os casos geridos pela estrutura estatal, de responsabilidade da escola quando em seu interior, e delegados às cooperativas sociais para a realização do trabalho técnico intra ou extra-classe.

Não existem escolas especiais, existem instituições especiais, como aquelas destinadas aos cegos por exemplo, que atuam integradamente com as escolas, preparando crianças e adolescentes para a tarefa árdua da autonomia. As crianças freqüentam esses institutos em horários extra-classe e aprendem a usar o computador, recebem estimulação psico-sensorial, apoio psicológico, pedagógico e psicomotor. Outras instituições se ocupam da profissionalização de jovens com limitações físicas e mentais, preparando-os e integrando-os no mercado de trabalho. Existe uma estrutura apreciável de atendimento aos sujeitos ditos especiais que sofistica-se constantemente com o surgimento de novas necessidades.

O welfare state nas sociedades européias, estabelecido a partir de 1946, visava inicialmente evitar a marginalização de sujeitos e grupos no período pós guerra. Desde então, tem sido continuamente debatido e revisado

${ }^{6}$ Traduzido livremente do texto da lei. e já foi considerado inúmeras vezes no limite de sua capacidade de proteção social, tanto do ponto de vista econômico quanto conceitual. Porém, é inegável que os sistemas de segurança social sustentam uma sociedade democrática onde a saúde, a educação, entre outras condições básicas de vida são garantidas a todos. Como característica essencial de sua existência, esse sistema encontra-se continuamente confrontado com a necessidade de revisão e acolhimento de novos grupos de diversos.

\section{Diversidade: é possível defini-la sem reduzi-la?}

Ao falar sobre o direito a assistência sanitária, ou direito à saúde, Foucault (2000) refere a necessidade de pensá-lo a partir de uma linha móvel, que redefiniria continuamente o significado desse direito na prática. A linha móvel depende de muitos fatores, mas no caso do direito à saúde depende dos avanços científicos para suprir tecnicamente as crescentes necessidades sociais, da capacidade econômica de uma coletividade, e das prioridades dessa coletividade, ou seja, de como deseja transformar seus recursos em atendimento a saúde. Em outras palavras, o direito à saúde, assim como os limites de acesso à saúde, são flexíveis e exigem redefinição constante: "É necessário ter em mente que esses limites não podem ser estabelecidos uma vez por todas através de uma definição médica de saúde, nem pela idéia de 'necessidades de saúde' expressas como absolutas". (Foucault, 2000, p.375).

É importante notar o quanto essa proposta aproximase ao conceito flexível de normalidade proposto por Canguilhem (1990), onde o ambiente e a mudança de condições de vida, situacionais ou definitivas, podem provocar uma transformação no que é considerado norma ou normalidade. O welfare state é um exemplo da linha móvel proposta por Foucault, pois é continuamente redirecionado para satisfazer e controlar a crescente complexidade social.

A idéia da linha móvel parece muito apropriada para discutir diversidade, uma vez que esse também é um conceito flexível e, portanto, não pode ser definido arbitrariamente. O que era diverso na sociedade de Basaglia continua, sem dúvida, sendo até hoje, se pensarmos na necessidade contínua de inserção social de sujeitos portadores de sofrimento psíquico. Da mesma forma, a lei da escola continua beneficiando pessoas diversas, procurando integrar os portadores de deficiências no convívio social, evitando marginalizá-los em estruturas "especiais". Essas foram leis que garantiram e continuam garantindo os direitos desses grupos de diversos. Permanecendo no ambiente escolar assinalamos novas tensões provocadas por um novo tipo de diversidade. A linha móvel do conceito diversidade assinala que o diverso hoje é o diverso cultural, o estrangeiro com hábitos, cor de pele e religião diferentes.

Pensar nesses termos faz com que aceitemos definições simples de diversidade como aquela proposta por Jelloun (1998), ou seja, "a diversidade é o contrário da semelhança, daquilo que é idêntico". Esse tipo de definição nos recoloca a questão que o conceito diversidade não é 
esgotável. Segundo o mesmo autor, a diversidade não é necessariamente fonte de rejeição e cita como exemplo a atração entre diferentes sexos. Porém, reconhece a existência de outras diferenças que impactam e provocam reações, desde a surpresa e a curiosidade, passando pela rejeição, até a completa intolerância.

Um relatório do ano escolar 2001/2002 indicava 181.767 alunos estrangeiros na escola italiana, 2,31\% do total de alunos, provenientes de 186 paises diferentes ${ }^{7}$. É um número pequeno se comparado com outros paises europeus, mas significativo para a Itália onde a presença de estrangeiros na escola tem crescido muito rapidamente; dez anos atrás os estrangeiros em classe eram $25.000^{8}$. A escola é um canal privilegiado de integração desses sujeitos, uma vez que muitos vivem em comunidades étnicas muito fechadas e, em certos casos, distantes das influências das culturas que as hospedam.

$\mathrm{Na}$ experiência da escola italiana percebe-se que os alunos estrangeiros ocupam uma posição de desvantagem devido a muitos aspectos. Em primeiro lugar, a aprendizagem da língua é extremamente valorizada e isso significa aprender sutilezas muito precocemente, que são enfatizadas em casa e nos anos iniciais de escolarização. Sendo a língua italiana muito fonética, falar italiano vai além da pronúncia das letras, envolve um conjunto de sons e pausas muito especial e que lhe confere a sonoridade poética. A comunicação é mais complexa do que possa parecer e é feita dessas sutilezas, inicialmente imperceptíveis para quem fala italiano como segunda língua. Mesmo que uma pessoa fale gramaticalmente correto, o fato de ter algum sotaque ou cometer pequenos erros de pronúncia muitas vezes vem confundido com baixo nível cultural.

Por outro lado, muitos italianos, ainda pouco habituados a presença de estrangeiros, não conseguem manter a atenção concentrada por muito tempo no discurso de alguém que não decifrou ainda essas sutilezas. A contrapartida inevitável é a inibição e o sentimento de rejeição da parte daquele que não é ouvido. A comunicação é desencorajada muitas vezes devido a certas expressões faciais, tipo enrugar a testa e olhos como se estivesse fazendo um esforço para entender; ou devido a aceleração da fala do outro, através de expressões do tipo "O que tu queres dizer é...", ou "Entendi, entendi...". Não são poucas também as situações em classe onde professores corrigem os alunos dizendo que os mesmos não são estrangeiros e por esse motivo não devem falar errado. Isso é feito na presença dos alunos estrangeiros. Expressões do tipo "nós aqui fazemos desse modo", são dirigidas aos estrangeiros demarcando muito claramente as diferenças culturais.

É considerado ponto pacífico que os alunos estrangeiros atrasam o programa didático da classe. Algumas escolas, em regiões com maior concentração de estrangeiros, estão propondo experiências de formarem classes exclusivas para esses alunos. Pode-se pensar que

\footnotetext{
${ }^{7}$ Isso significa "o mundo na escola", uma vez que são 195 o total de nações reconhecidas como tais no mundo.

8 "Alunni con cittadinanza non italiana - anno scolastico 20012002”. EDS - Servizio di Consulenza all'Attività Programmatoria, Ministero dell'Istruzione, dell'Università e della Ricerca.
}

é um momento inicial de discussão e afrontamento do problema mas, inegavelmente, faz pensar também a um retorno das classes especiais.

As questões didáticas não são as únicas a provocarem confronto cultural no interior da escola, a religião é um outro ponto de atrito. Recentemente, estabeleceu-se um forte debate a partir da solicitação de uma associação islâmica, paralela ao pedido de uma associação laica italiana, da retirada de crucifixos das salas de aula, alegando que os símbolos de outras religiões não estão representados nas escolas. A opinião pública dividiu-se entre uma maioria que defendia a permanência de um símbolo da tradição católica, e os que achavam razoável a solicitação de uma escola laica, ou de convívio entre religiões. Muita polêmica foi gerada, quase nenhuma solução. O que resultou mais evidente foi a radicalização de ambos os lados, sem que algum tipo de negociação fosse estabelecida.

Mesmo os intelectuais não conseguiram assumir uma posição clara com receio de ir contra a opinião geral. $\mathrm{O}$ apelo às tradições serve como instrumentalização e defesa frente ao novo, privando a sociedade de uma oportunidade de reflexão e de abertura. O que prevalece é a sensação de ser "atacado" pelo outro, de ter que defender-se emocionalmente confirmando a religião ou a cultura dominante. A escola laica está prevista na constituição italiana e qualquer mudança na mesma não depende somente da solicitação de membros de uma outra religião. Como a cultura dominante é católica, a "normalidade" significa ter aulas de religião ou símbolos da mesma em classe, mesmo que desde muito tempo as famílias possam optar por frequentar às aulas ou não.

\footnotetext{
A escola pública é na realidade entendida, coerentemente, como um espaço comum onde se é educado para o espírito crítico, onde qualquer um leva suas convicções com a palavra, mas sem nunca ocupá-lo com símbolos de uma adesão parcial, de uma identidade que pela sua natureza exclui. Um espaço é público porque nele a única identidade e adesão que pode prevalecer é aquela comum a todos, de ser cidadão. O resto, por mais que seja difuso, é privado. (D’Arcais, 2003, p.5)
}

É importante a idéia de que mesmo difuso, ou pertencente à maioria, a religião - assim como política, valores, hábitos - é uma questão privada que não pode ser considerada um padrão de comportamento a ser adotado geral e indiscriminadamente. Mantovani (2004, p.8) discutindo o etnocentrismo e o relativismo cultural como interpretações parciais de cultura, propõe o interculturalismo como espaço de trocas e possibilidade de inovação das tradições. Concorda com Benhabib (2005, p.31) que considera a cultura como uma construção narrativa compartilhada, continuamente contestada e negociada, “das imaginárias fronteiras entre 'nós' e o "outro",.

A autora parte da ética discursiva e da negociação dos envolvidos para a adoção de uma determinada norma. Os problemas a serem discutidos, ou o significado de determinada norma a ser adotada, são estabelecidos através de processos dialógicos que incluem discursos morais, éticos e político-pragmáticos. Por exemplo, 
algumas vezes o diálogo moral serve para individuar uma questão legislativa, mais do que discutir moralidade em si mesma. O importante é que as pessoas que participam da discussão cheguem a uma interpretação das normas e de suas aplicações.

A imigração é uma questão social importante nos dias atuais e reflete-se sobremaneira na escola. O movimento de populações que fogem da pobreza ou da guerra em seus paises, dirige-se a paises mais ricos e estáveis, criando desigualdades sociais já esquecidas nesta parte do mundo desde o tempo da Segunda Guerra e do estabelecimento do welfare state. O problema não é pequeno ou desprezável, e tem gerado casos de intolerância nas sociedades receptoras, que se vêem confrontadas com uma série de novos problemas resultantes da imigração. Bauman (2005) chama de "rejeitos humanos"9 as pessoas colocadas à margem da sociedade globalizada e pósindustrial. Vivemos em um mundo em que certos indivíduos não têm mais colocação, seja em termos de trabalho como de vida em geral. $\mathrm{O}$ autor distingue o momento atual daquele da sociedade industrial, que mantinha um exército de reserva pronto a ser readmitido na dinâmica social, mesmo com dificuldades inerentes a desqualificação. Hoje, o excedente humano deve praticamente perder as esperanças de ser reaproveitado e deve viver, na melhor das hipóteses, dos escassos subsídios estatais, ou ser completamente marginalizado em sociedades menos estruturadas para atender suas necessidades. A idéia do mundo de desiguais está presente também no trabalho de Sennett (2004), que reconhece a desigualdade como inerente a sociedade e observa que a mesma era já considerada inexorável na formulação do welfare state.

Como já refletia Basaglia (2000) em suas conferências brasileiras, a realidade externa é soberana e não muda somente através de belos discursos ou boa vontade. $\mathrm{O}$ trabalho necessário à conscientizaçao e à mudança é muito maior, como ele mesmo demonstrou através de sua luta anti-manicomial. Se queremos mudar as condições dos sujeitos que sofrem por serem diversos, devemos considerá-los sujeitos reais, que têm necessidades e relações concretas, e não interpretá-los através de uma perspectiva ideal e abstrata. "Se queremos sair dessa situação ${ }^{10}$, devemos tentar construir um novo umanesimo $^{11}$, devemos dar uma nova forma ao homem, devemos criar os pressupostos para que o outro não seja um inimigo" (Basaglia, 2000, p.62).

Entre posições pessimistas ou negociadas, a questão diversidade é premente e exige ações mais efetivas do que o simples suceder normal dos fatos da vida. A

\footnotetext{
${ }^{9}$ Traduzido para o italiano, do original inglês "Wasted lives", como "Vite di Scarto".

${ }^{10}$ Referia-se ao impasse entre discurso e prática, entre o mundo concreto e as idéias, mais precisamente entre a realidade concreta do Juqueri e a da conferência que estava proferindo naquele momento em São Paulo (21 de junho de 1979).

${ }^{11}$ Resistimos em traduzir umanesimo como humanismo, em primeiro lugar, porque umanesimo refere-se a concepção de homem renascentista, como ator e produtor da vida, portanto resultado de uma revolução no pensamento humano, nas artes e na ciência; em segundo lugar, para não associar as idéias de Basaglia com correntes de pensamento chamadas humanistas.
}

educação ao diverso deve seguir seu rumo, identificando e priorizando as novas demandas sociais. Na realidade aceitar o diferente não é algo que nos ocorre espontaneamente, depende de educação e de sensibilização; com certeza depende também de dominação cultural, de poder econômico, de outros aspectos importantes mas muito amplos para aprisionar em uma única discussão. Aceitar o diferente significa ser aberto ao contraste, ao questionamento de certezas, à tolerância ao sofrimento e às limitações. Sujeitos prontos a esse enfrentamento tornam-se mais compreensivos e menos egoistas em relação às necessidades dos outros, assim como mais sensíveis às questões coletivas.

O trabalho de Basaglia, de denúncia das condições a que os doentes psiquiátricos eram submetidos, mas não somente isso, também suas tentativas de mudar idéias cristalizadas de vida e de relações, foram feitas através de narrativas de situações, que a primeira vista podem ser interpretadas como caricaturais. As denúncias para serem eficientes devem ser constantes, a ponto de transformar a incredulidade inicial em empatia e, enfim, em adesão à causa reivindicada. Como se comportaria o motorista de táxi, referido por Basaglia, nos dias atuais? Seria capaz de fantasiar com um sujeito um pouco estranho que quer ir a Beirute em seu táxi, mas muito provavelmente sonhe também com a possibilidade real de mandar tantos outros diversos que povoam sua cidade, seu trabalho, a escola de seus filhos, para Tirana, La Paz, Sarajevo, Sofia, Bucharest, Bogotá, Zagreb, Quito, São Paulo, Asmara, Adis Ababa, Tripoli, Dakar, Kinshasa, Harare.

\section{Referências}

D’Arcais, P. F. (2003). Il crocifisso e la democrazia. Lettera aperta agli amici credenti. Roma: MicroMega, Almanacco di Filosofia.

Basaglia, F. (2000). Conferenze Brasiliane. Milano: Raffaello Cortina.

Bauman, Z. (2005). Vite di Scarto. Roma: Laterza.

Benhabib, S. (2005). La rivendicazione dell'identità culturale: eguaglianza e diversità nell'era globale. Bologna: Il Mulino.

Canguilhen, G. (1990). O Normal e o Patológico. Rio de Janeiro: Forense.

Foucault, M. (2000). Essential Works of Foucault 1954-1984 (Vol. 3). London: Penguin Books.

Giannella, S. (1977). La fine del nido del cuculo. Milano: L'Europeo.

Jelloun, T. B. (1998). Il razzismo spiegato a mia figlia. Milano: Passagi Bompiani.

Mantovani, G. (2004). Intercultura: è possibile evitare le guerre culturali? Bologna: Il Mulino, 2004.

Sennett, R. (2004). Rispetto: la dignità umana in un mondo di diseguali. Bologna: Il Mulino.

Maria Beatriz Rodrigues é Psicóloga, PhD em Development Studies pela Sussex University, Inglaterra. Atualmente é vinculada a Coperativa Social Ce.Se.Co., Genova. Endereço: Via Barassi, 5 B, 16033, Lavagna, (GE), Itália. Itália. E-mail: biarodrigues@hotmail.it

\section{Maria Beatriz Rodrigues}

Quais são as nossas diferenças?

Reflexões sobre a convivência com o diverso em Escolas Italianas Recebido: 29/05/2005

$1^{\text {a }}$ revisão: $07 / 11 / 2005$

Aceite final: 22/12/2005 